\title{
TRÂNSITO RELIGIOSO NO BRASIL
}

\author{
Ronaldo de Almeida \\ Professor da Escola de Sociologia e Política, Pesquisador do Cebrap \\ Paula Montero \\ Diretora do Museu de Arqueologia e Etnologia da USP, Pesquisadora do Cebrap
}

\begin{abstract}
Resumo: O campo religioso sofreu transformações nas últimas décadas que levaram à fragmentação institucional e à intensa circulação de pessoas pelas novas alternativas religiosas. Este artigo pretende caracterizar a configuração atual do campo religioso brasileiro a partir de dados sociodemográficos de uma pesquisa nacional realizada para o Ministério da Saúde e, num segundo momento, formular um fluxograma exploratório do padrão de migração de pessoas e crenças entre as religiões.

Palavras-chave: religião; mobilidade; Igreja Universal; Renovação Carismática.
\end{abstract}

$\mathrm{D}$ e modo geral, a literatura científica sobre o campo religioso brasileiro tem sido desafiada por um curioso paradoxo: o acúmulo de conhecimento sobre as diferentes cosmovisões parecia ter tornado evidente que, do ponto de vista dos ritos, das crenças e da lógica interna de cada universo, os cultos podem ser considerados bastante diferentes entre si, mas, quando se observa o comportamento daqueles que freqüentam esses cultos, as fronteiras parecem pouco precisas devido à intensa circulação de pessoas pelas diversas alternativas, além da acentuada interpenetração entre as crenças. A pesquisa Comportamento Sexual da População Brasileira e Percepções do HIV/Aids, realizada em todo o Brasil, em 1998, revelou que $26 \%$ da população mudou de religião. ${ }^{1}$ Concomitante à circulação de pessoas, ocorreu também a multiplicação das alternativas religiosas, encontrando sua expressão máxima entre os evangélicos, cuja fragmentação institucional é estrutural ao seu próprio movimento de expansão. Nesse processo sempre renovado de divisão por "cissiparidade", as denominações continuamente dão origem a novos grupos. ${ }^{2}$

Essa aparente contradição entre o modo como especialistas e adeptos percebem o campo religioso representa um desafio para a interpretação científica que, muitas vezes, tem se contentado em adjetivá-lo de fluido, híbrido, sincrético ou contínuo. O conceito weberiano de "conversão", que até muito recentemente explicava o complexo processo subjetivo de adesão a um novo credo, não parece mais capaz de elucidar essas rápidas idas e vindas entre religiões aparentemente tão díspares entre si: um processo interior em que a consciência religiosa não acusa, pelo menos à primeira vista, incongruências cognitivas.

Uma das tentativas para compreender esse fenômeno reduziu a diversidade religiosa à metáfora do mercado. Estaria subjacente a esse enquadramento do pluralismo a idéia de que a racionalização do sagrado no mundo moderno realizar-se-ia pela transformação das crenças em mercadorias a serem consumidas pelos adeptos que, volúveis, escolheriam os produtos segundo suas necessidades imediatas. A redução do fenômeno do trânsito religioso ao processo de mercantilização dos bens de salvação acabou por deixar na sombra os mecanismos particulares de ressignificação das crenças religiosas. Em ensaio de 1994, sugeriu-se que as diferentes tradições religiosas estão em permanente processo de reinvenção e rearticulação muitas vezes responsável pelo obscurecimento da nitidez das fronteiras. Desse ponto de vista, a circulação entre os diferentes códigos seria estimulado pela existência de um substrato cognitivo e/ou cultural comum às religiões populares brasileiras, fundado seja em uma idéia abstrata de deus que incorpora todas as variantes, seja em uma representação ambígua e não dicotômica da idéia de mal (Montero, 1994). Um exemplo disto é a Igreja Universal do Reino de Deus, que pode ser entendida como resultan- 
te da interação entre uma tradição evangélica-pentecostal e um catolicismo afro-kardecista, articulada em torno da figura do diabo (Almeida, 1996). Outros estudos apontam na mesma direção ao demonstrarem que, entre a "malineza" dos encantados da cultura amazônica, dos demônios do catolicismo popular e dos evangélicos e os "exus" das religiões afro-brasileiras, haveria a permanência de uma concepção ética particular às camadas populares (Birman, Novaes e Crespo, 1997).

Esse macroprocesso de contínua síntese e diferenciação é o fenômeno que aqui interessa ser descrito. A literatura especializada convencionou denominá-lo, por economia, de trânsito religioso. Esta noção aponta, pelo menos, para um duplo movimento: em primeiro lugar, para a circulação de pessoas pelas diversas instituições religiosas, descrita pelas análises sociológicas e demográficas; e, em segundo, para a metamorfose das práticas e crenças reelaboradas nesse processo de justaposições, no tempo e no espaço, de diversas pertenças religiosas, objeto preferencial dos estudos antropológicos.

O problema se coloca, portanto, em dois níveis de análise: um propriamente institucional, que descreve a mudança das filiações; e outro mais cognitivo, que mostra as semelhanças e as diferenças entre as representações dos universos religiosos. A partir desses níveis, este artigo objetiva, em primeiro lugar, desenhar a configuração atual das principais tradições religiosas e suas características sociodemográficas e, em segundo, compreender alguns fluxos preferenciais nesse trânsito generalizado de fiéis e idéias religiosas. Preferenciais porque a intensidade da circulação varia de acordo com as instituições envolvidas, como se houvesse fluxos mais intensos entre algumas do que entre outras. Trabalha-se com a hipótese de que as pessoas não mudam de religião de maneira aleatória. A movimentação ocorre em direções precisas, dependendo das instituições envolvidas. Algumas são preferencialmente "doadoras", enquanto outras são mais "receptoras"; algumas trocam adeptos entre si, enquanto em outras são as crenças que circulam mais. Nossa proposta é formular um fluxograma exploratório do trânsito religioso ocorrido no Brasil nestas últimas décadas.

\section{CARACTERIZAÇÃO SOCIOECONÔMICA DOS RELIGIOSOS}

Os católicos foram os que mais perderam fiéis em números absolutos nas últimas décadas. Contudo, apesar da volumosa perda, o catolicismo mantém-se como o maior grupo religioso no Brasil, com $67,4 \%$ da população, dividido equilibradamente entre os sexos, com maior concentração nas regiões Norte/Nordeste e sendo mais confesso por pessoas com idade superior a 41 anos e jovens com menos de 25 anos. Em parte, este último dado se explica pelo fato de as pessoas herdarem a religião dos pais e iniciarem preferencialmente - se for o caso - um processo de mudança religiosa quando mais velhas. O quadro geral, portanto, é de perda de católicos, tendo como base os dados censitários de 1980 e 1991. Mantida esta tendência, muito provavelmente essa geração que se encontra entre 26 e 40 anos produzirá, em alguns anos, uma popu-

TABELA 1

Distribuição dos Indivíduos de 16 a 65 anos, por Sexo, Estratos Amostrais e Faixas Etárias, segundo Religião Atual Brasil - 1998

\begin{tabular}{|c|c|c|c|c|c|c|c|c|c|c|}
\hline \multirow[b]{3}{*}{ Religião Atual } & \multirow[b]{3}{*}{ Total } & & & & & & & & & porcentage \\
\hline & & \multicolumn{2}{|c|}{ Sexo } & \multicolumn{3}{|c|}{ Estratos Amostrais } & \multicolumn{4}{|c|}{ FaixaEtária } \\
\hline & & Homens & Mulheres & CentroX & NorNor & SulX & $\begin{array}{c}16 \text { a } 25 \\
\text { Anos }\end{array}$ & $\begin{array}{c}26 \text { a } 40 \\
\text { Anos }\end{array}$ & $\begin{array}{c}41 \text { a } 55 \\
\text { Anos }\end{array}$ & $\begin{array}{c}56 \text { a } 65 \\
\text { Anos }\end{array}$ \\
\hline Católica & 67,4 & 66,3 & 68,3 & 67,9 & 74,2 & 64,3 & 68,3 & 64,7 & 68,5 & 72,8 \\
\hline Pentecostal & 11,8 & 9,0 & 14,4 & 12,2 & 7,8 & 13,5 & 12,0 & 11,6 & 13,8 & 7,3 \\
\hline Protestantismo Histórico & 5,2 & 6,2 & 4,3 & 7,0 & 6,3 & 4,3 & 4,7 & 3,9 & 6,4 & 9,4 \\
\hline Espírita Kardecista & 2,9 & 2,7 & 3,1 & 3,4 & 2,0 & 3,2 & 1,2 & 4,1 & 3,8 & 1,3 \\
\hline Afro-brasileira & 0,5 & 0,5 & 0,5 & 0,6 & 0,7 & 0,3 & 0,4 & 0,2 & 0,9 & 1,0 \\
\hline Outra & 2,2 & 1,1 & 3,3 & 1,0 & 1,6 & 2,8 & 1,6 & 2,6 & 1,0 & 5,7 \\
\hline Sem Religião & 9,7 & 13,9 & 5,9 & 7,9 & 6,8 & 11,5 & 11,4 & 12,6 & 5,3 & 2,6 \\
\hline Não Respondeu & 0,2 & 0,3 & 0,2 & 0,0 & 0,5 & 0,2 & 0,4 & 0,2 & 0,2 & 0,0 \\
\hline
\end{tabular}

Fonte: Ministério da Saúde. Pesquisa sobre Comportamento Sexual da População Brasileira e Percepções sobre HIV/Aids. 
TABELA 2

Distribuição dos Indivíduos de 16 a 65 Anos, por Grau de Instrução, segundo Religião Atual

Brasil - 1998

\begin{tabular}{lcccrrr}
\hline Religião Atual & Analfabeto & Fundamental Incompleto & Fundamental Completo & Médio Completo & Superior & Total \\
\hline Total & $\mathbf{6 , 3}$ & $\mathbf{4 6 , 0}$ & $\mathbf{2 1 , 7}$ & $\mathbf{1 6 , 7}$ & $\mathbf{9 , 4}$ & $\mathbf{1 0 0 , 0}$ \\
Católica & 6,9 & 44,4 & 21,7 & 17,0 & 10,0 & 100,0 \\
Protestantismo Histórico & 9,1 & 41,8 & 24,1 & 20,8 & 4,2 & 100,0 \\
Pentecostal & 5,0 & 65,2 & 18,0 & 9,1 & 1,0 & 18,0 \\
Espírita Kardecista & 0,0 & 12,9 & 25,4 & 42,7 & 100,0 \\
Afro-brasileira & 0,0 & 41,6 & 21,1 & 1,3 & 100,0 \\
Sem Religião & 4,5 & 46,6 & 21,4 & 14,3 & 13,1 & 100,0 \\
Outra & 4,2 & 44,4 & 30,8 & 16,3 & 4,3 & 100,0 \\
\hline
\end{tabular}

Fonte: Ministério da Saúde. Pesquisa sobre Comportamento Sexual da População Brasileira e Percepções sobre HIV/Aids.

TABELA 3

Distribuição dos Indivíduos de 16 a 65 Anos, por Estratos Socioeconômicas, segundo Religião Atual Brasil - 1998

\begin{tabular}{|c|c|c|c|c|c|c|}
\hline \multirow{2}{*}{ Religião Atual } & \multicolumn{6}{|c|}{ Estratos Socioeconômicos } \\
\hline & A & B & $\mathrm{C}$ & $\mathrm{D}$ & $\mathrm{E}$ & Total \\
\hline Total & 4,2 & 21,3 & 35,9 & 30,3 & 8,3 & 100,0 \\
\hline Católica & 4,6 & 22,3 & 33,0 & 29,9 & 10,3 & 100,0 \\
\hline Protestantismo Histórico & 3,0 & 17,9 & 36,3 & 39,1 & 3,7 & 100,0 \\
\hline Pentecostal & 1,5 & 8,9 & 47,3 & 38,5 & 3,8 & 100,0 \\
\hline Espírita Kardecista & 3,6 & 58,4 & 29,9 & 7,0 & 1,1 & 100,0 \\
\hline Afro-brasileira & 0,0 & 36,9 & 22,2 & 40,9 & 0,0 & 100,0 \\
\hline Sem Religião & 7,1 & 17,0 & 44,4 & 25,7 & 5,7 & 100,0 \\
\hline Outra & 1,1 & 31,4 & 35,6 & 27,7 & 4,2 & 100,0 \\
\hline
\end{tabular}

Fonte: Ministério da Saúde. Pesquisa sobre Comportamento Sexual da População Brasileira e Percepções sobre HIV/Aids.

lação ainda menos católica, devido ao crescimento vegetativo de outras religiões, além da sua capacidade de atração de novos adeptos. Em contrapartida a esta projeção, a consolidação do movimento carismático pode inverter esse comportamento ao promover a "readesão" ao catolicismo.

Em relação à distribuição espacial, no Centro X, a participação dos católicos está próxima à média nacional, enquanto no NorNor encontra-se acima da média e, no SulX, abaixo. Esta divisão do país em três grandes regiões - que obedece aos objetivos da pesquisa citados anteriomente - requer maior precisão. ${ }^{3}$ De acordo com outras pesquisas, o Centro-Oeste é considerado uma região que recebeu um forte fluxo migratório poucas décadas atrás. Entre os migrantes, encontra-se um número expressivo de evangélicos vindos do Sul do país. Minas Gerais, ao contrário, é um Estado que, pelo Censo Demográfico de 1991, mostrava-se extremamente católico, acompanhando o comportamento do Nordeste: uma forte presença do catolicis- mo tradicional e popular das festas, procissões e romarias. Como Minas Gerais encontra-se no CentroX, a resultante da presença católica nesta região foi próxima à média nacional. O mesmo pode ser pensado para o NorNor, pois o Nordeste é muito católico e pouco evangélico, enquanto em Estados do Norte, como Rondônia, Pará e Amapá, houve migração recente com significativa presença evangélica proveniente do Sul do país. Contudo, como os Estados do Nordeste são mais populosos, a média de católicos no NorNor é significativamente superior à média do Brasil. Por fim, o dado encontrado para a área SulX é o mais próximo da realidade para todos os Estados: menor presença de católicos do que a média nacional. Destacam-se, nessa região, pentecostais, umbandistas, kardecistas e sem religião.

Em relação à escolaridade e à renda, os católicos, pelo fato de serem a maioria, obedecem ao padrão nacional, tendo em vista o "critério Brasil". ${ }^{4}$ Baseando-se em dados qualitativos, observa-se que muitas pessoas têm ou- 
tras práticas religiosas, mas identificam-se como "católico apostólico romano" quando perguntadas "qual é a sua religião?", principalmente entre os estratos mais pobres e menos escolarizados. Na verdade, trata-se de uma identidade religiosa pública, muito embora as crenças e práticas católicas ocupem um plano mais secundário na vida do fiel em relação ao condomblé, umbanda, espiritismo, entre outros.

A esse tipo de católico que mantém simultaneamente religiosidades diferentes - cada uma localizada num plano da vida do fiel - acrescentam-se ainda os chamados "não-praticantes", categoria sociologicamente pouco precisa, mas com uma auto-identificação significativa que compõe uma parcela importante do segmento. São os católicos dos batismos, casamentos e enterros, para os quais os sacramentos atuam como ritos de passagem tradicionais na sociedade brasileira. Trata-se daqueles indivíduos que acreditam na Igreja, batizarão seus filhos nela, aceitam-na como identidade religiosa, mas não a praticam, como ir periodicamente aos templos ou manter alguma devoção a um santo, por exemplo. A auto-identificação de "não-praticante" deve-se à pouca frequiência aos serviços religiosos e à ausência de relações mais comunitárias. Por meio de entrevistas qualitativas, é possível inferir que um número considerável de pessoas pode muito bem se identificar como católico "não-praticante", ou simplesmente sem religião, dependendo do dia em que for entrevistada. Não por acaso, curiosamente, entre aqueles que se encontram na categoria sem religião, $30,7 \%$ freqüentam algum serviço religioso anualmente e $20,3 \%$ mais de uma vez ao mês (Tabela 4).

Em relação aos afro-brasileiros, verifica-se que, para a alternativa "nunca frequienta serviços religiosos", o valor corresponde a zero (Tabela 4). Para o candomblé e a umbanda, a religiosidade está diretamente ligada às práticas rituais. Suas exigências não são do tipo comportamental, como entre os evangélicos, mas sim de cumprimento ritual de "dar comida para o santo". Além disso, o calendário ritual afro-brasileiro tem uma periodicidade mais espaçada do que o cristão: católicos e evangélicos (protestantes históricos e pentecostais). Porém, para os primeiros, a freqüência semanal à Igreja é pouco superior a $50 \%$, enquanto entre os pentecostais este índice chega a quase $90 \%$, número semelhante ao dos protestantes históricos e um pouco superior ao dos kardecistas.

De acordo com a Tabela 1, os pentecostais constituem o segundo maior segmento, com $11,8 \%$ da população, e apresentam a maior taxa de crescimento conforme os dois últimos Censos Demográficos. O grande contingente é feminino: $63,7 \%$ dos pentecostais, são mulheres - enquanto que a proporção feminina na população do Brasil é de $52,3 \%$-, só perdendo para a categoria outras religiões," com 77,0\% (sobre as quais nada se pode afirmar devido à variedade compreendida pela categoria). Contudo, algumas denominações pentecostais conseguem ter um índice ainda maior do que este. Quase $80 \%$ dos que freqüentam a Igreja Universal, por exemplo, são compostos por mulheres.

Em relação à escolaridade, a maioria dos pentecostais $(65,2 \%)$ é formada por pessoas com o fundamental incompleto (para a população brasileira, a média é de $46 \%$ ). A presença diminui relativamente nos extremos da escolaridade: poucos pentecostais entre os analfabetos e aqueles com ensino médio completo e menos ainda com nível superior (Tabela 2). Verifica-se comportamento semelhante na estratificação socioeconômica. Os pentecostais pre-

TABELA 4

Distribuição dos Indivíduos de 16 a 65 Anos, por Freqüência aos Serviços Religiosos, segundo Religião Atual Brasil - 1998

\begin{tabular}{|c|c|c|c|c|c|c|}
\hline \multirow[b]{3}{*}{ Religião Atual } & & & & & & iporcentagem \\
\hline & \multicolumn{6}{|c|}{ Freqüência aos Serviços Religiosos } \\
\hline & Nunca & Anualmente & $\begin{array}{c}\text { Mais de Uma } \\
\text { Vez ao Mês }\end{array}$ & Semanalmente & $\begin{array}{l}\text { Várias Vezes } \\
\text { por Semana }\end{array}$ & Total \\
\hline Total & 6,7 & 19,9 & 18,6 & 41,0 & 13,7 & 100,0 \\
\hline Católica & 3,2 & 22,6 & 22,6 & 46,1 & 5,5 & 100,0 \\
\hline Protestantismo Histórico & 0,3 & 7,3 & 4,2 & 43,7 & 44,5 & 100,0 \\
\hline Pentecostal & 0,7 & 7,9 & 4,8 & 34,4 & 52,2 & 100,0 \\
\hline Espírita Kardecista & 7,2 & 6,3 & 4,7 & 68,9 & 12,9 & 100,0 \\
\hline Afro-brasileira & 0,0 & 6,5 & 47,3 & 30,1 & 16,1 & 100,0 \\
\hline Sem Religião & 43,0 & 30,7 & 20,3 & 5,6 & 0,4 & 100,0 \\
\hline Outra & 1,5 & 6,3 & 9,6 & 39,1 & 43,5 & 100,0 \\
\hline
\end{tabular}

Fonte: Ministério da Saúde. Pesquisa sobre Comportamento Sexual da População Brasileira e Percepções sobre HIV/Aids. 
dominam mais nos estratos $\mathrm{C}$ e D e menos em A, B e E. Em suma, baixa e média escolaridade e renda caracterizam esses religiosos.

O segmento pentecostal é significativamente composto por jovens e adultos, sendo pequena a presença de pessoas com mais de 55 anos. Ao se distribuir a população total pelas faixas etárias, constata-se uma maior participação de pessoas mais velhas no catolicismo, no protestantismo histórico, e outras, enquanto os mais jovens optam, curiosamente, pela filiação aos segmentos católico e pentecostal, ou pela não filiação religiosa. Quanto aos católicos, vale a explicação anterior sobre a herança religiosa. Os outros (pentecostais e sem-religião) predominam nas faixas etárias de 16 a 25 anos e de 26 a 40 anos, ocupando cada um em torno de $12 \%$ da população em cada faixa. Esses dados apontam dois movimentos concomitantes, a princípio contraditórios. Um em direção a uma religiosidade exclusivista e espiritualizada, que insere o fiel em outra rede de sociabilidade, desencadeando nele mudança de comportamento. Neste pode-se incluir também a Renovação Carismática que, embora ocorra no interior do catolicismo, caracteriza-se pela incorporação de uma religiosidade tipicamente evangélica: pouca liturgia e muita música e gestos que dinamizam a celebração; ênfase na conversão e nos dons espirituais como o poder de cura, além de utilizar, assim como os evangélicos, os meios de comunicação como importante veículo de propagação da "fé católica renovada".

O outro movimento está direcionado à desfiliação ou à não-identificação com nenhuma instituição, que muitas vezes é acompanhada de desqualificação da vida religiosa. Assim, não só proliferam as religiões como também os sem-religião, que formam o terceiro maior grupo. Esta polaridade do campo religioso contribui para a discussão que ainda domina parte da sociologia da religião, qual seja, se esta mudança de configuração aponta para um "reencantamento do mundo" ou trata-se apenas de um ajuste da religião no macroprocesso de secularização, no qual se encontra a sociedade brasileira pelo menos desde a separação da Igreja do Estado (Montero e Almeida, 2000).

Os sem-religião apresentam um nível de escolaridade alta e, em relação à renda dos brasileiros, estão bastante presentes nos estratos A e C. Pelos dados não é possível estabelecer uma relação direta entre maior filiação religiosa e estrato socioeconômico baixo. Os sem-religião encontram-se mais entre jovens e adultos até 40 anos e, principalmente, entre os homens. Em relação ao sexo dos religiosos, a pesquisa mostra que há predominância mas- culina somente nas alternativas sem religião - numa relação de quase dois homens para uma mulher - e protestantismo histórico. Em geral, a religiosidade é mais confessa pelas mulheres. Logo, em alguma medida, a distinção de gênero afeta o processo de secularização.

O protestantismo histórico forma o quarto maior grupo, com 5,2\% da população, e comporta uma maioria masculina. Estes religiosos encontram-se mais entre as pessoas que possuem ensino fundamental (incompleto e completo) e médio completo, bem como nos estratos B, C e, principalmente, D (Tabela 2). Assim, como os católicos, os protestantes históricos encontram-se mais presentes entre as pessoas acima de 41 anos e mais ainda entre aqueles com idade superior a 56 anos. Os protestantes estão pouco presentes entre os mais jovens, sendo que o aumento vegetativo deste segmento é inferior ao católico e a taxa de crescimento é pequena. Contudo, assim como ocorreu com o catolicismo, eles foram atingidos também pelo movimento carismático que tem atraído muitos fiéis e criou um segmento religioso com características intermediárias entre protestantes históricos e pentecostais: são os protestantes carismáticos ou renovados.

Os kardecistas, com 2,9\% dos brasileiros, são os religiosos com maior nível de escolaridade e renda. Nenhum caso de analfabetismo foi registrado entre os entrevistados, poucos possuíam ensino fundamental incompleto e completo e muitos tinham médio completo e superior. Quanto à renda, este segmento está mais concentrado nos estratos D e B. ${ }^{5}$ Curiosamente, as religiões afro-brasileiras possuem maior participação entre as classes altas e com maior escolaridade, muito embora a experiência mostre que muitos pobres são adeptos dessas religiões. Recorrese novamente ao argumento anterior, para o qual boa parte dos brasileiros mantém uma religiosidade privada e outra (a católica) como identidade pública, principalmente se a resposta for dada no contexto de um survey, o que limita a caracterização de certas religiões.

\section{MOBILIDADE DOS RELIGIOSOS}

Como dito inicialmente, o quadro descrito é resultado de uma intensa circulação de pessoas entre as religiões, ocorrida nas últimas três décadas. De acordo com as características sociodemográficas, o universo feminino tem um nível de filiação maior do que o dos homens, mas isto não significa que as mulheres mantenham a religião herdada; ao contrário, são elas as que mais mudam e, na maior parte das vezes, sempre direcionadas para outras religiões. 
O SulX, por sua vez, foi a única região onde as pessoas mudaram de filiação acima da média nacional, criando o cenário mais plural do Brasil. Os muito pobres com pouquíssima escolaridade e os muito ricos e de alta escolaridade mudaram muito menos de religião. Em resumo, a mudança ocorreu de forma mais concentrada no SulX, nas classes $\mathrm{C}$ e $\mathrm{D}$, com escolaridade baixa e média e entre as mulheres, segmentos em que os pentecostais mais se proliferaram.

Em números absolutos, os católicos foram os que mais perderam. Em seguida vêm os sem-religião, os protestantes históricos, os pentecostais e pouquíssimos kardecistas e afro-brasileiros. Por outro lado, os segmentos que mais receberam pessoas, em ordem crescente, foram: os pentecostais (quatro vezes mais do que perdeu); sem-religião (cerca de metade a mais); protestantes históricos (quase igual ao que perderam); católicos; kardecistas; e afro-brasileiros. Porém, ao reduzir o universo unicamente aos
$26,5 \%$ que mudaram de religião, quais são as principais conexões entre as alternativas religiosas? Isto é, quem recebeu de quem e quem doou para quem? É como se quiséssemos saber, por exemplo, de onde vieram os fiéis do kardecismo e para onde vão os kardecistas quando mudarem de religião. Para construir esse movimento, a pesquisa perguntou a religião atual do entrevistado e em qual ele foi criado. Desta maneira, cada religião pôde ser analisada em dois momentos: como pontos de recepção e de emissão de fiéis. Considerando-se o estoque de pessoas de cada uma dessas categorias e a alta circulação interna, o campo religioso brasileiro pode ser articulado em torno de três principais vértices.

O primeiro vértice é formado pelos católicos, que funcionam como uma espécie de "doador universal", de onde todos os segmentos arregimentam boa parte dos seus fiéis. O grupo preferencial para onde migram os católicos é o pentecostalismo, seguido por aquele sem religião. Do

TABELA 5

Distribuição dos Indivíduos que Mudaram de Religião, por Religião em que foi Criado, segundo Religião Atual

Brasil - 1998

Emporcentagem

\begin{tabular}{|c|c|c|c|c|c|c|c|c|}
\hline \multirow[b]{2}{*}{ Religião Atual } & \multicolumn{8}{|c|}{ Religião em que foi Criado } \\
\hline & Católica & $\begin{array}{l}\text { Protestantismo } \\
\text { Histórico }\end{array}$ & Pentecostal & $\begin{array}{c}\text { Espírita } \\
\text { Kardecista }\end{array}$ & Afro-brasileira & Nenhuma & Outra & Total \\
\hline Total & 100,0 & 100,0 & 100,0 & 100,0 & 100,0 & 100,0 & 100,0 & 100,0 \\
\hline Católica & - & 12,2 & 36,7 & 63,6 & 24,1 & 20,3 & 23,9 & 9,0 \\
\hline Protestantismo Histórico & 14,9 & - & 0,6 & 0,0 & 9,3 & 31,1 & 1,9 & 12,8 \\
\hline Pentecostal & 36,5 & 3,0 & - & 5,6 & 11,1 & 46,3 & 39,7 & 31,1 \\
\hline Espírita Kardecista & 13,5 & 0,3 & 2,5 & - & 0,0 & 0,0 & 2,8 & 9,0 \\
\hline Afro-brasileira & 2,3 & 0,1 & 0,0 & 0,0 & - & 0,0 & 0,0 & 1,5 \\
\hline Sem Religião & 23,6 & 79,5 & 58,8 & 29,6 & 55,6 & - & 31,7 & 29,9 \\
\hline Outra & 9,2 & 4,9 & 1,4 & 1,2 & 0,0 & 2,2 & - & 6,7 \\
\hline
\end{tabular}

Fonte: Ministério da Saúde. Pesquisa sobre Comportamento Sexual da População Brasileira e Percepções sobre HIV/Aids.

TABELA 6

Distribuição dos Indivíduos que Mudaram de Religião, por Religião em que foi Criado, segundo Religião Atual Brasil - 1998

\begin{tabular}{|c|c|c|c|c|c|c|c|c|}
\hline \multirow[b]{2}{*}{ Religião Atual } & \multicolumn{8}{|c|}{ Religião em que foi Criado } \\
\hline & Católica & $\begin{array}{c}\text { Protestantismo } \\
\text { Histórico }\end{array}$ & Pentecostal & $\begin{array}{c}\text { Espírita } \\
\text { Kardecista }\end{array}$ & Afro-brasileira & Nenhuma & Outra & Total \\
\hline Total & 63,6 & 9,4 & 7,6 & 2,0 & 0,3 & 10,0 & 6,9 & 100,0 \\
\hline Católica & - & 12,7 & 31,0 & 14,4 & 0,9 & 22,6 & 18,4 & 100,0 \\
\hline Protestantismo Histórico & 74,0 & - & 0,3 & 0,0 & 0,2 & 24,4 & 1,0 & 100,0 \\
\hline Pentecostal & 74,8 & 0,9 & - & 0,4 & 0,1 & 14,9 & 8,9 & 100,0 \\
\hline Espírita Kardecista & 95,4 & 0,4 & 2,1 & - & 0,0 & 0,0 & 2,2 & 100,0 \\
\hline Afro-brasileira & 99,6 & 0,4 & 0,0 & 0,0 & - & 0,0 & 0,0 & 100,0 \\
\hline Sem Religião & 50,1 & 25,0 & 14,9 & 2,0 & 0,6 & - & 7,3 & 100,0 \\
\hline Outra & 87,8 & 6,9 & 1,6 & 0,4 & 0,0 & 3,3 & - & 100,0 \\
\hline
\end{tabular}

Fonte: Ministério da Saúde. Pesquisa sobre Comportamento Sexual da População Brasileira e Percepções sobre HIV/Aids. 
ponto de vista da recepção, quase metade das pessoas entrevistadas que aderiram ao catolicismo afirmou não ter pertencido anteriormente a nenhuma religião ou que eram pentecostais. Porém, como dito anteriormente, em parte o primeiro dado se explica pela fronteira pouco precisa entre os que se dizem católicos "não-praticantes" e os semreligião. Trata-se de um catolicismo dado pela tradição, em que as pessoas receberam a religião dos pais e a ativam no uso dos sacramentos e nos momentos de dificuldades pessoais (familiar, financeira, saúde, etc.), ou, mais recentemente, por meio da "readesão carismática".

Os kardecistas, por sua vez, orbitam em torno do catolicismo, formando um fluxo preferencial. A quase totalidade $(95,4 \%)$ afirmou ter sido católica e, quando as pessoas saem do kardecismo, vão (ou voltam) para o catolicismo, ou têm, como segunda opção, não ter religião. O fluxo de pessoas do (ou para o) catolicismo é explicado, em parte, pelo comportamento da maioria dos kardecistas, que, assim como os afro-brasileiros, não deixam de se identificar como cristãos e católicos: um "católico espírita”, cujos práticas não são excludentes, mas que, dependendo da situação, o indivíduo pode utilizar uma ou outra identidade. Os afro-brasileiros, em parte, orbitam em torno do catolicismo como os kardecistas, mas, diferentes destes, a maioria das pessoas, quando sai das religiões afro-brasileiras, declara-se sem religião.

No segundo vértice encontram-se os sem-religião, categoria equivalente a um "receptor universal", que, numa sociedade em processo de secularização, recebe pessoas de todas as confissões. Acrescente-se, contudo, que a literatura antropológica demonstrou exaustivamente como muitas pessoas compõem um repertório particular de crenças e práticas variadas, mas não se identificam com nenhuma religião específica. Não se trata, portanto, somente de um movimento em direção ao ateísmo, mas sim a composição de um repertório simbólico particular, afinal, a não-filiação não significa necessariamente ausência de religiosidade. Um dos exemplos contemporâneos mais significativo de composição desses arranjos particulares é formado pelo circuito neo-esotérico, cuja religiosidade não se expressa prioritariamente pela filiação a uma instituição, mas é definida por um certo estilo de vida, fenômeno bastante presente nas classes média e alta dos grandes centros urbanos (Magnani, 1999).

Um fluxo significativo envolve ainda os sem-religião e protestantes históricos. Os históricos são semelhantes aos católicos, aumentando praticamente de forma vegetativa e perdendo fiéis quase na mesma proporção; contudo, diferentes dos católicos que aderem a todas as alternativas, a maior parte dos ex-protestantes $(79,5 \%)$ simplesmente fica sem religião. Neste caso, o comportamento é semelhante ao kardecismo, que se explica a partir dos conteúdos específicos dessas religiões que tendem à secularização, como uma religiosidade que pretende um caráter científico.

Finalmente, o terceiro vértice é formado pelos pentecostais, cujo aumento é semelhante ao daqueles sem-religião, mas, diferente destes, buscam seus fiéis entre alguns es-

FIGURA 1

Padrões de Migração entre Religiões

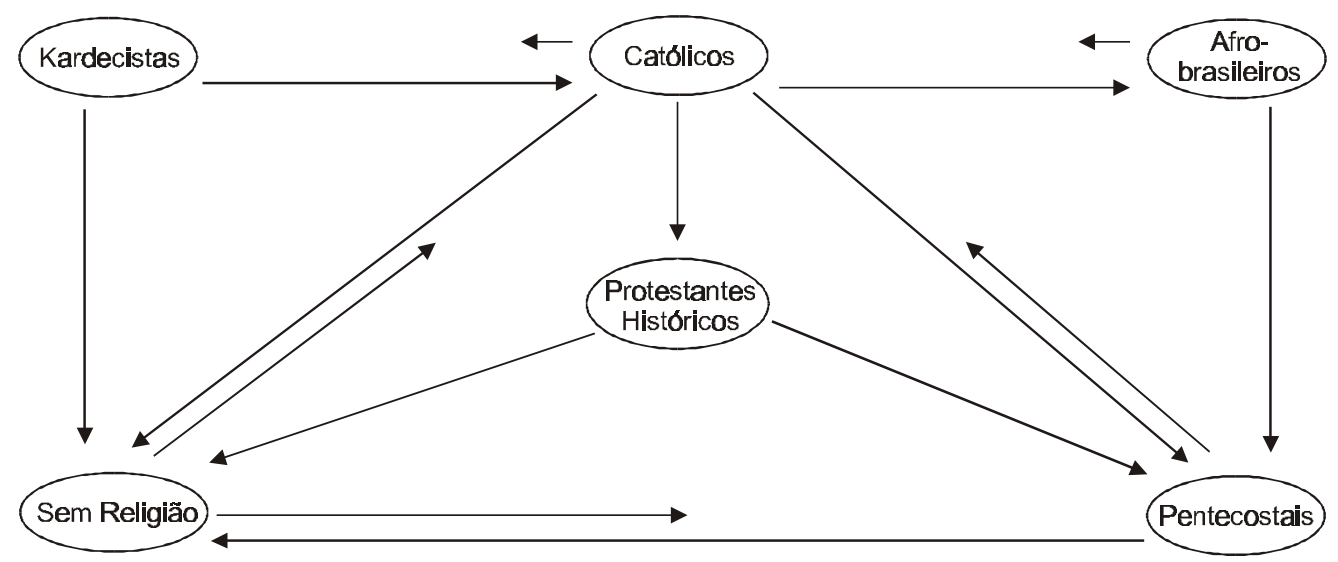

Fonte: Elaboração dos autores. 
tratos sociais e segmentos religiosos - basicamente entre católicos, afro-brasileiros e sem-religião, que compõem um repertório simbólico "católico-afro-kardecista" que manipula simultaneamente elementos de confissões diferentes: lógica mágica, reencarnação e destino, devoção a santos e crença na comunicação com os mortos. Os pentecostais pouco atraem os kardecistas - o que se explica pelas diferenças sociais que caracterizam estes segmentos -, mas confrontam-se com algumas de suas idéias como espíritos de mortos e reencarnação. Os afro-brasileiros, por sua vez, estão na esfera de ação dos pentecostais por serem alvos privilegiados da evangelização e modelo simbólico religioso a ser combatido. Porém, o grande celeiro dos pentecostais é formado pelo catolicismo. Neste sentido, a Renovação Carismática não deve ser entendida apenas como um movimento de readesão, mas também de reação ao avanço evangélico.

No cenário atual, pode-se entender a neopentecostal Igreja Universal, fundada em 1977, como resultante da interação, tanto simbólica quanto numericamente, dos universos evangélico e umbandista. A Igreja Universal construiu uma religiosidade que condenou - e ao mesmo tempo validou - os conteúdos de outras religiões, contudo, paradoxalmente, incorporou as formas de apresentação e certos mecanismos de funcionamento de um prática encontrada particularmente na umbanda. Ela ficou mais parecida com a religiosidade inimiga ao elaborar um sincretismo às avessas, que associou as entidades da umbanda e orixás do candomblé ao pólo negativo do cristianismo: o diabo. Se originalmente os universos foram formados em contextos diferentes, a interação (produto do trânsito de pessoas e idéias) gerou uma religiosidade que mistura exus com glossolalia, exorcismo com transe; de tal maneira que se estabeleceu uma continuidade pela qual as entidades conseguiram transitar e esses universos puderam, pelo transe, se comunicar. Os pares negação/ inversão e assimilação/continuidade são os mecanismos fundamentais pelos quais se processaram essa antropofagia religiosa. Graças a esses binômios, a Universal pôde manter o proselitismo de fiéis e, ao mesmo tempo, ser sincrética com outras crenças, que, juntamente com os infortúnios vividos pela população brasileira, formam o alimento constitutivo do seu simbolismo religioso (Almeida, 1996).

Outro fluxo significativo gerador de um novo padrão de religiosidade foi formado pela interação entre catolicismo, pentecostalismo e protestantismo histórico, resultando na Renovação Carismática. A penetração de alguns elementos evangélicos no catolicismo ocorreu em duas dimensões: do pentecostalismo, a Renovação adotou os dons espirituais ou carismas, como a glossolalia e a cura; e do protestantismo histórico, a idéia de conversão pessoal que, em termos práticos, manifesta-se como experiência emocional com implicações direta no comportamento do fiel em esferas da vida social, como a família e o trabalho, e ainda no seu estado psíquico-emocional (depressão, vício, solidão, etc.). A conversão ocorre como internalização da religião acompanhada de mudança de comportamento social e reorganização da vida em torno de uma "comunidade de irmãos". Contudo, a conversão evangélica tem implícita a necessidade de dissidência institucional e uma nova filiação. Porém, como aderir ao catolicismo se já nasci católico? A contribuição da Renovação é conseguir operar uma mudança, "ser um novo homem", sem romper com a Igreja. Na verdade, ela promove a "re-adesão" a um novo corpo de fiéis atingido pela religiosidade evangélica dentro da própria Igreja. Um fluxo em torno de si mesmo. O resultado é um fiel que junta glossolalia com o culto mariano, o que garante catolicidade ao movimento. ${ }^{6}$

\section{CONCLUSÃO}

Neste artigo, não se tentou assentar a discussão nas lógicas internas dos diferentes credos, mas sim compreender como estas rebatem umas nas outras, e em planos distintos. Seria interessante, portanto, retomar de maneira mais sistemática, noções que perpassam as diversas religiões, tais como a dicotomia bem/mal, justiça, pecado, pobreza, sofrimento, salvação, etc., com a finalidade de acompanhar com maior precisão as migrações religiosas. Promover um espelhamento entre as religiões, para apreender zonas de tensão e regiões de fusão, definido pela simultaneidade de interações que são desiguais entre si.

Citam-se a Universal e a Renovação por considerá-las os produtos mais recentes das transformações do campo religioso brasileiro. É como se, a partir delas, fosse possível recuperar parte do processo de interação das tradições católica, evangélica e afro-kardecista. Esses exemplos mostraram o espraiamento do pentecostalismo pelo catolicismo e pelo protestantismo histórico (dando origem aos carismáticos e renovados) e, simultaneamente, a absorção de práticas e crenças da umbanda, que, por sua vez, é resultado da articulação entre os universos kardecista e afrobrasileiro com a mediação do catolicismo, este sim, o grande doador não só de pessoas, mas também de um campo 
semântico comum às religiões no Brasil. Diante deste cenário, "o campo religioso será ainda hoje o campo das religiões?", para refazer a pergunta-título de um artigo de Pierre Sanchis (1995).

Mencionando novamente a pesquisa sobre "Comportamento Sexual da População Brasileira e Percepções do HIV/Aids", as perguntas sobre a mobilidade religiosa eram: "qual a sua religião atual" e "em qual você foi criado". Essas perguntas têm dois limites metodológicos: o cruzamento só mede uma mudança de religião e pressupõe que, no momento da entrevista, o indivíduo só tenha uma filiação. Pela característica do campo brasileiro, não é nenhum absurdo supor uma trajetória que apresentasse mobilidade institucional (num processo de sucessivas "conversões") ou a simultaneidade de vários credos (como se fosse um sincretismo privado).

Isto posto, ao invés de citar um dado etnográfico específico, suponhamos um movimento ideal no campo. Comecemos por um religioso de referência, tão comum no Brasil: o católico "não-praticante". Um indivíduo que passou pela Igreja em momentos como batizado, talvez uma comunhão e uma crisma, o casamento e, no futuro, receberá dela a extrema-unção - alguém que pode muito bem se declarar sem religião, dependendo do dia em que for entrevistado, mas, ao descobrir ser portador de uma grave doença, recorrerá à fé católica, aos santos milagreiros e a alguma devoção a Maria. Não conseguindo o seu objetivo, recorre à umbanda, que lhe promete a cura mediante oferenda de sacrifício para alguma entidade afro-brasileira. A cura, no entanto, não vem. Ele, então, assiste na televisão os testemunhos de milagres que ocorrem a quem for à Universal; e lá se fixa o fiel-doente. A partir de pesquisa na Igreja Universal, pode-se afirmar que até aqui essa trajetória é significativamente observável.

Envolvido com o meio evangélico, esse sujeito pode seguir ainda dois caminhos. Primeiro, passar para outras igrejas históricas. A pesquisa Novo Nascimento pode levar a esta conclusão, uma vez que $25 \%$ dos evangélicos pertenceram a mais de uma denominação (Fernandes et alii, 1998). O único problema é que o fluxo ocorre preferencialmente das históricas para as pentecostais, e muito pouco no sentido inverso. Um outro caminho possível, mas que precisa de constatação empírica, é o fiel-doente aprender a doutrina da conversão e do Espírito Santo na Renovação Carismática e voltar à religião da sua tradição: o catolicismo.

Evidente que esse conjunto de passagens representa uma trajetória ideal, porém, como dito, plausível de acordo com a bibliografia sociológica e antropológica. Não se entende que exista uma relação de determinação entre as duas circulações, na qual a mobilidade de fiéis seria o suporte pelo qual o conteúdo religioso fluiria. Ou o inverso disso: que a invenção religiosa torna mais plausível para uns do que para outros a mudança de filiação. As circulações devem ser entendidas em planos distintos, porém correlatas, como se houvesse uma retroalimentação que acelerasse tanto a mobilidade de fiéis quanto o trânsito de práticas e crenças, resultando na invenção religiosa e em novos agrupamentos de pessoas. Acredita-se, contudo, que essa correlação e interpenetração devem ser indicadas, em primeiro lugar, na trajetória do indivíduo (daí a necessidade de melhorar as perguntas sobre pertença religiosa, associando-as a dados qualitativos) e não propriamente na instituição. Os circuitos se concretizam e se tornam mais claros na trajetória do indivíduo, sendo que o acúmulo de experiências proporcionadas pelo trânsito torna o seu repertório religioso mais amplo do que o pregado pela instituição à qual se filiou em determinada etapa da vida.

\section{NOTAS}

E-mail dos autores: ronaldo@cebrap.org.bre pmontero@usp.br

Agradecemos a preciosa ajuda de Marta Rovery de Souza e Eduardo Marquês, na análise dos dados quantitativos, de Maria Dirce G. Pinho e Maria Paula Ferreira, pela preparação do banco de dados e tabulações.

1. Esta pesquisa, cuja representatividade da amostra (3.600 indivíduos, entre 16 e 65 anos, moradores das áreas urbanas de 169 microrregiões do Brasil) tem capacidade de inferência da ordem de 77,7\% do universo (constituído, em 1996, por 77.018.818 pessoas), foi realizada pela área de População e Sociedade do Cebrap para o Ministério da Saúde, sob a coordenação da Dra. Elza Berquó. Seu objetivo principal foi "identificar representações, comportamento, atitudes e práticas sexuais da população brasileira e conhecimento sobre HIV/Aids, com vistas a estabelecer estratégias de intervenções preventivas das DSTs e HIV" (Coordenação Nacional de DST/Aids, 2000:11). No questionário foram incluídas sete perguntas (num total de 204) para compreender como as diferentes religiões influenciam o comportamento sexual. Este artigo vale-se das perguntas sobre religião e as referentes às características socioeconômicas da população para discutir um outro problema: a intensa mobilidade das pessoas pelas religiões, que também foi constatada por outras pesquisas, mas em universos menores, como o município de São Paulo (Prandi, 1996) e a Região Metropolitana do Rio de Janeiro (Fernandes et alii, 1998).

2. O dicionário de dados do Censo Demográfico, que serve de orientação para o entrevistador do IBGE, apresentava, em 1980, nove alternativas para a questão sobre filiação religiosa, passando para 51, em 1991. Estas 51 alternativas também foram utilizadas para classificar as respostas dos entrevistados da pesquisa Comportamento Sexual da População Brasileira e Percepções do HIV/Aids e, posteriormente, agregadas em sete grandes categorias que expressam as principais tradições religiosas no Brasil: católicos, protestantes históricos, pentecostais, afro-brasileiros, kardecistas, outras e sem religião.

3. A pesquisa dividiu o território nacional em três grandes regiões: CentroX (que compreende o Centro-Oeste mais os Estados de Minas Gerais e Espírito Santo), NorNor (Norte e Nordeste) e SulX (Sul e Sudeste, menos Minas Gerais e Espírito Santo).

4. "Nele são associados valores ao número de bens de consumo existentes no domicílio e ao nível de instrução do chefe da família e/ou pessoa de referência. Também são considerados, para essa classificação, o acesso ao número de automóveis e a existência de empregadas mensalistas. Este novo critério de pontua- 
ção permite uma maior aproximação da realidade socioeconômica dos entrevistados, além de poder ser utilizado como proxy da renda familiar" (Coordenação Nacional de DST/Aids, 2000:32).

5. Outras pesquisas confirmam este alto perfil socioeconômico dos kardecistas (Almeida e Chaves, 1998)

6. Destaca-se este aspecto por considerá-lo um dos mais significativos desse hibridismo religioso, porque Maria, para os evangélicos, não pode ser considerada a mãe de deus e tampouco objeto de culto, assim como nenhum santo.

\section{REFERÊNCIAS BIBLIOGRÁFICAS}

ALMEIDA, R. A universalização do Reino de Deus. Dissertação de Mestrado. Campinas, IFCH/Unicamp, 1996.

ALMEIDA, R. e CHAVES, M.F. "Juventude e filiação religiosa". Jovens acontecendo na trilha das politicas públicas. Brasília, Comissão Nacional de População e Desenvolvimento, 1998.

BIRMAN, P.; NOVAES, R. e CRESPO, S. (orgs.). O mal à brasileira. Rio de Janeiro, UFRJ, 1997
COORDENAÇÃO NACIONAL DE DST/AIDS. Série Avaliação. Brasília, Ministério da Saúde, n.4, out. 2000.

FERNANDES, R. et alii. Novo nascimento: os evangélicos em casa, na política e na igreja. Rio de Janeiro, Mauad, 1998.

MAGNANI, J.G. Mystica urbe: um estudo antropológico sobre o circuito neoesotérico na metrópole. São Paulo, Studio Nobel, 1999.

MONTERO, P. "Magia, racionalidade e sujeitos políticos". Revista Brasileira de Ciências Sociais. São Paulo, ano 9, n.26, out. 1994.

MONTERO, P. e ALMEIDA, R. "O campo religioso brasileiro no limiar do século: problemas e perspectivas" In: RATTNER, H. (org.). Brasil no limiar do século XXI. São Paulo, Edusp, 2000.

PIERUCCI, F. e PRANDI, R. A realidade social das religiões no Brasil. São Paulo, Hucitec, 1996.

PRANDI, R. "Religião paga, conversão e serviço". Novos Estudos. São Paulo, Cebrap, n.45, jun. 1996.

SANCHIS, P. "O campo religioso será ainda hoje o campo das religiões?” In: HOORNAERT, E. (org.). História da igreja na América Latina e no Caribe (1945-1995). Petrópolis, Vozes/Cehila, 1995. 